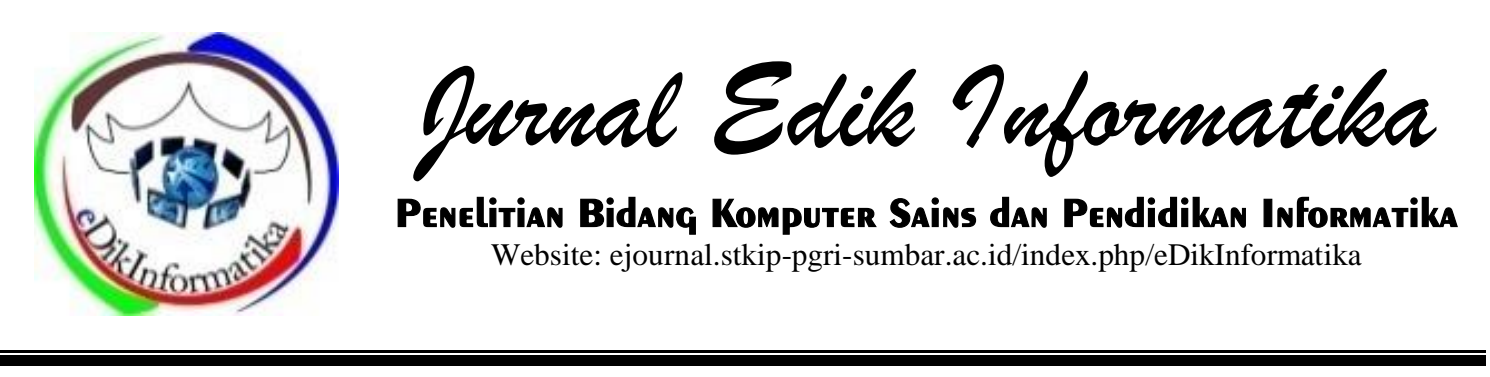

\title{
RANCANG BANGUN SISTEM INFORMASI PENJUALAN BARANG CV. FENNY DENGAN METODE WATERFALL
}

\author{
Susy Rosyida ${ }^{1}$ \\ ${ }^{1}$ Universitas Nusa Mandiri \\ susyrosyida@gmail.com
}

\section{INFO ARTIKEL}

Diterima:

10 Februari 2021

Direview:

18 Maret 2021

Disetujui:

03 Mei 2021

Kata Kunci:

Information Systems, Sales of Goods, Waterfall

\begin{abstract}
CV Fenny is a business or a trading business in the field of food or daily necessities. $C V$ the information system. Fenny still uses a manual system, which is inversely proportional to the increase in the number of customers and sales turnover. Therefore, the information needs cannot be or less so CV. Fenny is difficult to meets a consumer demand. Because the data collection was not structured and found some duplicate data. The storage and the search for transaction data have not been neatly arranged, because they only rely on the manual recording, and the storage is still using file cabinets which result in the accumulation of documents, processing errors in calculating sales results, making reports at the end of each period, as well as the large number of sales data that is not updated, there is no data security for a transaction process. The process of making sales data reports be less accurate, fast, and perfect because it has to collect all the transactions that occur, so, it takes longer. The method used in the design of the sales an information system CV. Fenny uses the waterfall method and uses the TELOS an eligibility factor to identify this sales an information system. With the CV sales system. Desktop-based Fenny can solve these obstacles, simplify, accelerate, improve the performance of $\mathrm{CV}$ employees. Fenny, simplifies the sales a transaction process, generates automatic calculations, so that, no errors occur in every report creation, and maintains the security of sales system data.
\end{abstract}

\section{PENDAHULUAN}

Teknologi informasi terutama dalam bidang komputer memegang peranan yang sangat penting dalam berbagai aspek kehidupan manusia, baik itu aspek ekonomi, pendidikan maupun sosial. Hal ini disebabkan oleh banyak faktor, salah satunya kerena penggunaan komputer memberikan kemudahan dan menunjukan kemampuannya untuk mendukung seluruh aktivitas kehidupan manusia, misalnya penjualan barang, pengajaran, penyampaian informasi dan sebagainya. Sebelum komputer menjadi 
sarana kebutuhan pokok dalam aktivitas komputerisasi perdagangan, penjualan barang, masih menggunakan sistem manual (Maslim, Adithama, \& Nugroho, 2020) dalam pengerjaan pencatatan dan transaksinya. Proses ini dinilai dan dianggap tidak efektif serta tidak efisien. Oleh karena itu perlu menggunakan penerapan teknologi yang lebih baik, dan dari sekian banyak pilihan teknologi yang ada dan yang memenuhi kebutuhan tersebut adalah komputer. Dengan menggunakan komputer kita dapat mengolah data menjadi suatu informasi yang lebih efektif dan efisien serta dapat meningkatkan keuntungan (Syaputra, Mardika, \& Akhirina, 2021) karena sesuai dan sinkron dengan kebutuhan saat ini. Data yang diolah mampu berperan sebagai apa saja sesuai kebutuhan, antara lain proses pengolahan data yang membentuk informasi mengenai transaksi penjualan yang terjadi, penginputan persediaan barang, sampai dengan pembuatan laporan penjualan pada setiap akhir periode. Dengan mengandalkan pengolahan data yang baik sangat dibutuhkan oleh sebuah perusahaan dengan menggunakan pengolahan data yang terkomputerisasi akan dapat meningkatkan efektivitas dan efisiensi untuk membantu pimpinan dalam proses pengambilan keputusan (Perdana, Agustine, Sholeh, \& Sujana, 2020), sebagai akibatnya pengorganisasian atau pengolahan data tersebut menaikkan kinerja pegawai.

Pada penelitian sebelumnya, proses penjualan masih menggunakan cara manual yaitu mencatat laporan melalui buku sehingga menyebabkan hilangnya data transaksi penjualan, stok, ketelitian dibutuhkan waktu yang lama saat pencatatan transaksi penjualan, melihat laporan, dengan membangun sistem aplikasi tidak lagi menggunakan cara manual, sistem dapat mencatat transaksi penjualan, mengurangi kesalahan pengelola toko, meningkatkan efisiensi waktu dan dapat mencetak laporan (Asroni, Jeckson, \& Basri, 2020). Pencatatan transaksi menggunakan cara konvensional masih menggunakan waktu yang lama, kesalahan perhitungan sehingga harus berulang-ulang dan pencarian data masih manual, dengan adanya sistem informasi pengelolaan penjualan perhitungan transaksi lebih akurat, membantu pengecekan stok dan pembuatan laporan lebih cepat dan mudah (Ansirwan, Mary, \& Irsyadunas, 2020)

CV Fenny adalah salah satu usaha atau bisnis dagang pada bidang pangan atau kebutuhan sehari-hari. Usaha atau bisnis ini telah lama dijalankan dan banyak masyarakat yang berada pada wilayah sekitar CV. Fenny membeli untuk kebutuhan sehari-hari atau untuk diperjualbelikan kembali dari rumah ke rumah, sekolah, warung kelontong, dan lain-lain. Hal ini disebabkan karena harga yang dijual terjangkau oleh masyarakat sekitar dan lebih rendah dari harga pasaran pada umumnya. Namun sistem informasi CV. Fenny masih menggunakan sistem manual, berbanding terbalik dengan meningkatkan jumlah pelanggan serta meningkatnya omset penjualan (Efriyanti, Garaika, \& Irviani, 2018). Karena itu sebagai akibatnya kebutuhan informasi tidak dapat atau kurang terpenuhi dan mengakibatkan peningkatan kinerja pegawai CV. Fenny sulit untuk tercapai dalam memenuhi permintaan konsumen.

Berdasarkan observasi yang sudah dilaksanakan sebelumnya, dapat diidentifikasi masalah-masalah yang terjadi sebagai berikut: 1). Dengan rancang bangun program sistem informasi penjualan secara komputerisasi, dapat meningkatkan kecepatan dalam memperoleh informasi tentang penjualan yang terjadi dalam setiap hari atau per periode, karena 
pendataan tidak terstruktur dan ditemukan beberapa data yang rangkap (Lubis, 2016). 2). Sistem komputerisasi yang dibangun mampu mengolah transaksi penjualan menjadi lebih baik lagi. 3). Penyimpanan dan pencarian data transaksi belum tersusun dengan rapih, lantaran hanya mengandalkan pencatatan manual serta penyimpanan masih menggunakan lemari file yang mengakibatkan penumpukan dokumen, dan sebagai akibatnya sulit untuk menemukan kembali data transaksi yang telah lama bila dibutuhkan. 4). Proses pembuatan laporan data penjualan yang kurang akurat, cepat dan sempurna karena harus mengumpulkan dulu seluruh transaksi yang terjadi, sebagai akibatnya akan membutuhkan waktu lebih lama (Fajriani, 2021). 5). Perlu adanya keamanan dalam sistem pengolahan data, agar dapat diketahui siapa yang melakukan proses transaksi tersebut.

Tujuan dari penelitian ini yaitu: 1). Pemanfaatan teknologi sistem informasi berbasis desktop agar memudahkan kinerja pegawai $\mathrm{CV}$. Fenny. 2). Meningkatkan kualitas penjualan dalam hal pelayanan kepada konsumen atau pelanggan dan meningkatkan kecepatan kinerja pegawai CV. Fenny. 3). Mempercepat dan mempermudah proses transaksi (Fahrezi, 2021) penjualan, pembayaran serta laporan transaksi agar lebih cepat dan akurat serta memenuhi target yang telah ditetapkan pimpinan. Hal ini memungkinkan berkurangnya terjadinya kesalahan dalam proses perhitungan hasil penjualan dan dalam pembuatan laporan setiap akhir periode, serta banyaknya data penjualan tidak terupdate karena masih dilakukan secara manual oleh kinerja pegawai CV. Fenny. 4). Untuk mengurangi penggunaan kertas pada pencatatan sehingga lebih menghemat biaya administrasi. 5). Jika pengguna lupa password karena password default terlalu sulit dapat mengakibatkan pengguna lupa passwordnya, oleh karena itu pengguna dapat mengganti password lama dengan password baru selain itu untuk kemananan pada sistem pengolahan data. 6). Dengan adanya perubahan, pemugaran dan penyempurnaan tadi dapat menaikkan pelayanan pada pelanggan, sebagai akibatnya dapat meningkatkan kepuasan konsumena atau pelanggan yang lebih besar sehingga daya beli masyarakat juga meningkat.

\section{METODE}

Untuk mendapatkan informasi tentang permasalahan pada CV. Fenny digunakan teknik pengumpulan data yaitu: 1). Observasi, sebagai cara untuk mengumpulkan data ataupun keterangan yang terkait menggunakan sistem informasi penjualan, di mana metode ini adalah output peninjauan eksklusif berdasarkan objek yang diamati baik itu data transaksi maupun laporan pada tiap akhir periode. 2). Wawancara, metode penelitian ini melakukan dengan cara menanyakan secara eksklusif baik pada pemilik, pegawai dan konsumen atau pelanggan guna menerima keterangan dan data serta untuk menambah wawasan keilmuan terkait hal yang belum diketahui dalam hal manajemen usaha. 3). Studi pustaka, penelitian ini ditunjang oleh beberapa buku yang menjadi tambahan pada penulisan misalnya pedoman penelitian, jurnal yang berhubungan dengan masalah pada penulisan penelitian ini.

Penyusunan penelitian menggunakan model pengembangan dengan metode waterfall. Metode waterfall terdiri dari beberapa langkah, yaitu: analisa, membuat desain, pembuatan kode program, pengujian dan pemeliharaan. Sedangkan bentuk kerangka pemikiran yang digunakan dapat dilihat pada Gambar 1. 


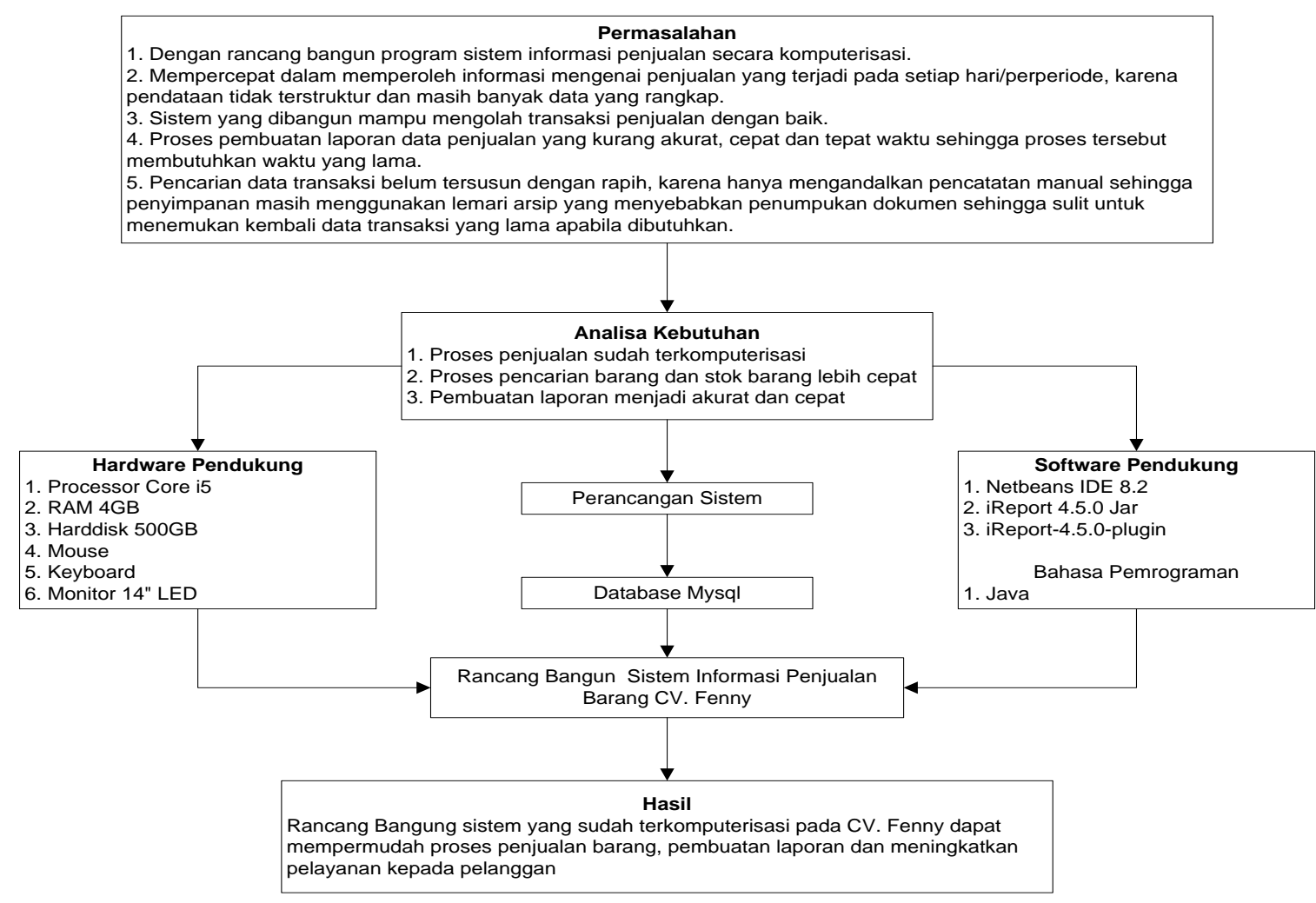

Gambar 1. Kerangka Pemikiran

\section{HASIL DAN PEMBAHASAN}

Melakukan pemetaan kegiatan penelitian bertujuan agar penelitian ini dapat menghasilkan sesuatu yang maksimal dan dapat bermanfaat bagi CV. Fenny tersebut. Adapun pemetaan penelitian ini meliputi:

\section{Analisa}

Pada tahap analisa terdiri telah ditemukan beberapa hal terkait dengan proses penjualan, pengumpulan data serta pembuatan laporan.

\section{Proses Bisnis}

CV. Fenny dituntut untuk memberikan layanan yang terbaik, karena banyak pesaing yang memberikan pelayanan terbaik dan harganya terjangkau serta tuntutan perubahan jaman seiring perkembangan teknologi yang semakin canggih khususnya dalam teknologi informasi yaitu komputer.
Oleh karena itu, CV Fenny harus memperbaiki dalam hal pelayanan terutama dalam mengefesiensi waktu maupun keamanan dan keakuratan data pada saat terjadi transaksi penjualan. Saat ini sistem pengolahan data penjualan masih menggunakan sistem manual terdiri dari transaksi penjualan, pengolahan data dan pembuatan laporan.

Berikut ini proses yang sedang berjalan pada CV. Fenny:

a. Proses penjualan barang

Konsumen mengambil barang sesuai dengan yang dibutuhkan, lalu karyawan melayani apa yang dibutuhkan konsumen tersebut, setelah selesai konsumen menerima barang apa yang diinginkan dan kasir mencatat pada nota penjualan, kemudian membayar sesuai dengan harga barang tersebut. 
b. Proses laporan penjualan Setelah adanya proses transaksi penjualan barang berakhir, kasir merekap seluruh data penjualan yang terjadi dan kemudian membuat laporan penjualan per harinya yang selanjutnya akan diberikan kepada pemilik sebagai laporan penjualan barang harian.

2. Analisa Faktor Kelayakan Technical, Economic, Legal, Operational dan Schedule (TELOS)
Faktor kelayakan TELOS yang dilakukan menggunakan cara dengan membagikan lembar kuesioner (Tabel 1) umum yang harus diisi pada CV. Fenny yang berisi pertanyaan-pertanyaan untuk mendapatkan nilai tentang kelayakan usaha/bisnis ini, TELOS terdiri berdasarkan 11 pertanyaan. Faktor kelayakan TELOS ini merupakan salah satu perbedaan dengan pnelitian sebelumnya.

Tabel 1. Lembar Kuesioner Penilaian Faktor Kelayakan TELOS

\section{Lembar Kuesioner Penilaian Faktor Kelayakan TELOS}

CV. Fenny

\begin{tabular}{lcccc}
\hline Pertanyaan & & Nilai & \\
\hline Kelayakan Teknik & $\mathbf{1}$ & $\mathbf{3}$ & $\mathbf{4}$ & $\mathbf{5}$ \\
\hline Apakah sistem yang dibentuk menggunakan teknologi & & & & $\checkmark$ \\
baru bagi perusahaan dan penguna? & & & & $\checkmark$ \\
Apakah perusahaan membutuhkan sistem yang baru? & & & \\
Apakah sistem baru merupakan sistem pertama yang & & & \\
dibangun? & & $\checkmark$ & \\
Apakah sistem yang dibangun merupakan sistem yang & & & \\
kompleks? & & & \\
\hline
\end{tabular}

\section{Kelayakan Ekonomi}

Apakah terdapat komitmen dari pemilik Perusahaan mengenai pendanaan?

Apakah terdapat dana pembangunan yang dialokasikan?

\section{Kelayakan Legalitas}

Apakah pihak perusahaan puas menggunakan sistem yang

dibentuk berdasarkan peraturan dan undang-undang

mengenai privasi?

Apakah sistem yang dibentuk dapat dikontrol dengan

baik?

\begin{tabular}{|c|c|c|c|c|c|}
\hline \multicolumn{6}{|l|}{ Kelayakan Operasional } \\
\hline $\begin{array}{l}\text { Apakah sistem yang dibentuk sederhana menggunakan } \\
\text { beberapa antarmuka? }\end{array}$ & & & \multicolumn{3}{|c|}{$\checkmark$} \\
\hline $\begin{array}{l}\text { Apakah sistem yang dibentuk dapat dipakai dengan } \\
\text { mudah? }\end{array}$ & & & \multicolumn{3}{|c|}{$\checkmark$} \\
\hline \multicolumn{6}{|l|}{ Kelayakan Jadwal } \\
\hline $\begin{array}{l}\text { Apakah pihak perusahaan puas dengan total waktu ketika } \\
\text { pembuatan sistem? }\end{array}$ & & & & $\checkmark$ & \\
\hline Jumlah & $\mathbf{0}$ & 2 & 1 & 5 & 3 \\
\hline Sub Total & $\mathbf{0}$ & 4 & 3 & 20 & 15 \\
\hline Total Nilai & & & 42 & & \\
\hline
\end{tabular}


Sedangkan untuk mengetahui output berdasarkan kuesioner uji kelayakan dapat diketahui berdasarkan range nilai, yaitu sebagai berikut:

$0-1.0=$ Tidak Layak

$1.1-2.0=$ Kurang Layak

$2.1-3.0=$ Cukup Layak

$3.1-4.0=$ Layak

$4.1-5.0=$ Sangat Layak

Berdasarkan hasil kuesioner yang sudah diberikan sebelumnya, dapat menghitung hasil akhirnya, yaitu:

Hasil $=$ Total Nilai $/$ Total Pertanyaan Hasil $=42 / 11=3.81$

Maka dapat disimpulkan bahwa dari hasil perhitungan faktor kelayakan TELOS yaitu 3.81, masuk ke dalam range $3.1-4.0$ yang berarti perancangan sistem informasi penjualan CV. Fenny adalah Layak. Dan ini harus lebih ditingkatkan lagi dengan sistem baru dan pelayanan yang lebih optimal.

\section{Desain}

Pada tahap desain yaitu membuat perancangan database, kemudian diterjemahkan ke dalam sistem melalui UML (Unified Modeling Language) dan desain database digambarkan melalui ERD (Entity Relationship Diagram).

Gambar 2. menggambarkan entity relationship diagram yang digunakan dalam membangun sistem informasi penjulan pada CV. Fenny. Pada database tersebut terdapat 4 tabel yang saling berelasi.

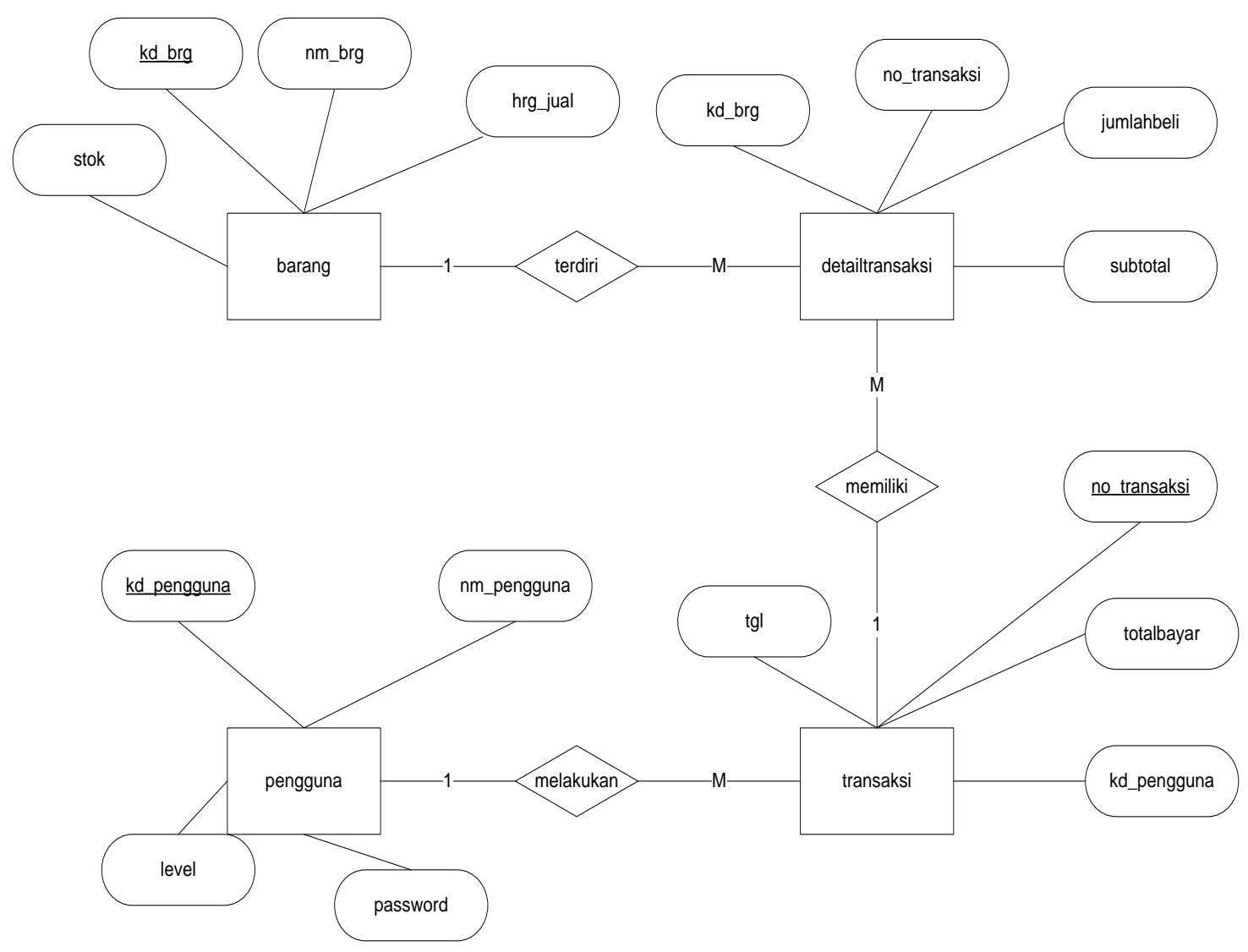

Gambar 2. Entity Relationship Diagram

Sumber: Hasil Penelitian 
Gambar 3. Menggambarkan use case diagram pada sistem yang dibangun untuk CV. Fenny. User yang mengakses sistem tersebut yaitu admin/pemilik dan kasir.

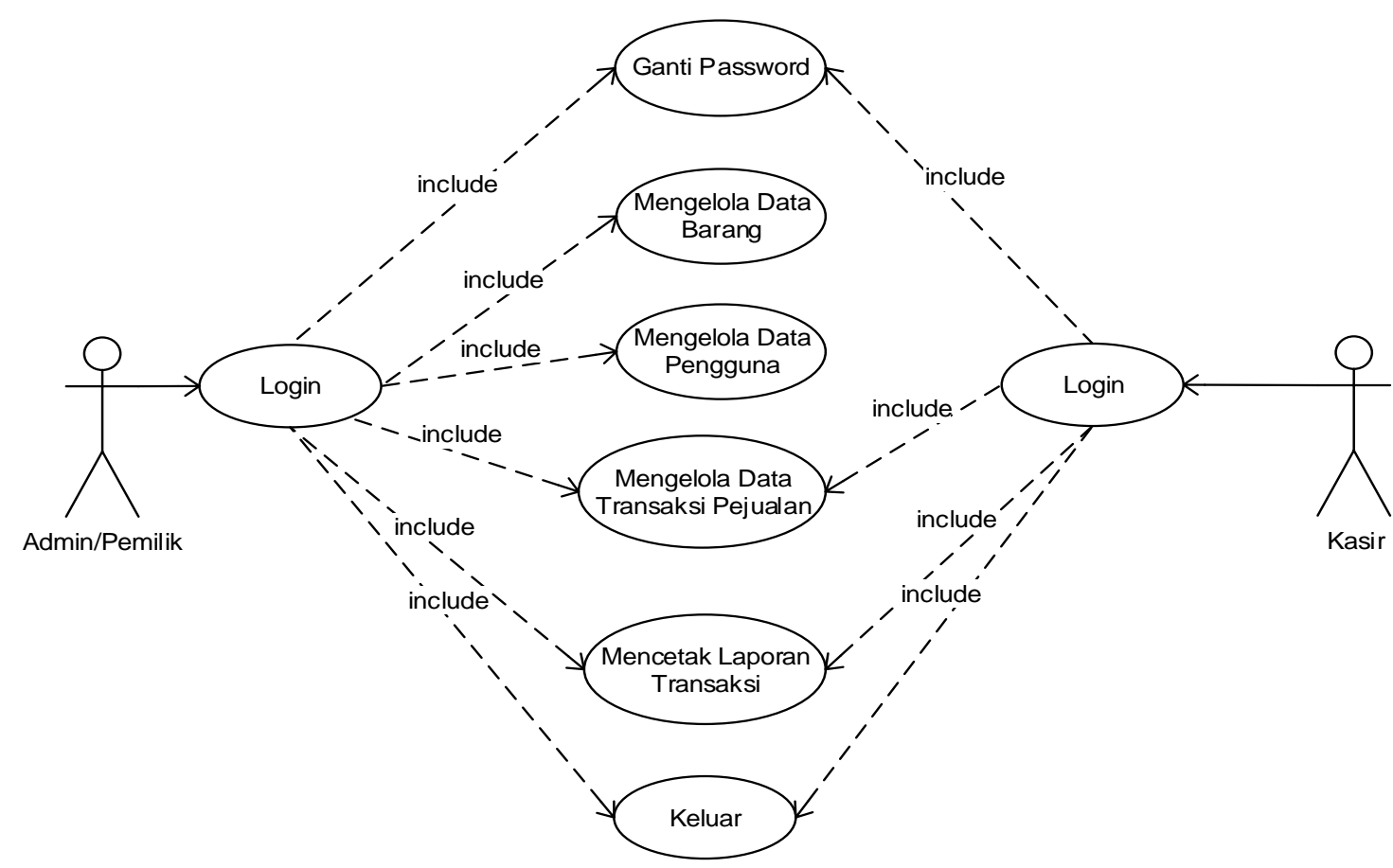

Gambar 3.Use Case Diagram

Sumber: Hasil Penelitian

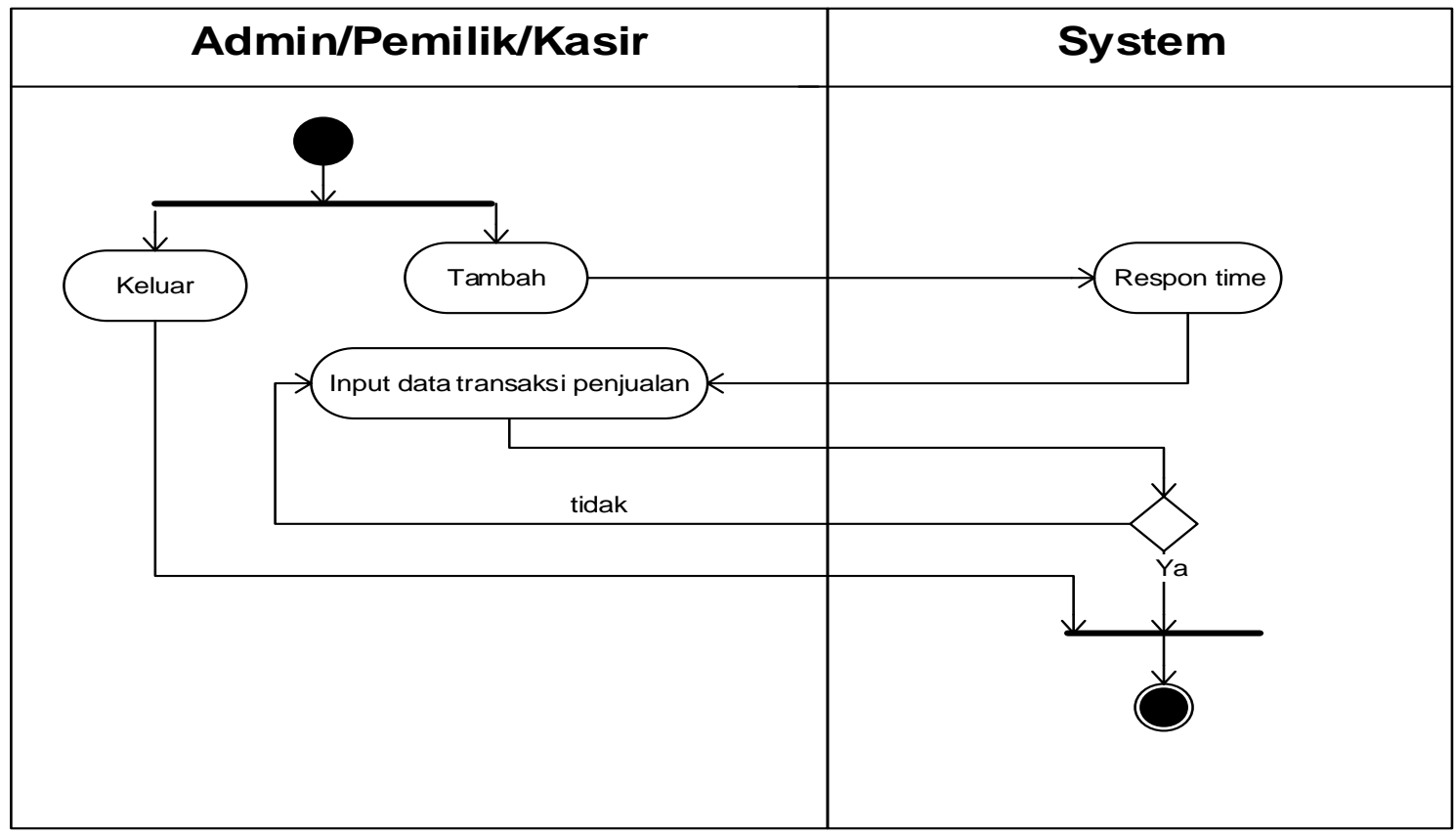

Gambar 4. Activity Diagram

Sumber: Hasil Penelitian 
Gambar 4. menjelaskan tentang activity diagram pada transaksi penjualan, dimana admin/pemilik/kasir yang dapat melakukan activity tersebut.

\section{Pembuatan Kode Program}

Setelah menuntaskan tahap desain, kemudian melanjutkan ke dalam tahap pengkodean program menggunakan bahasa pemrograman Java, database menggunakan MySQL, dan tools Netbeans IDE 8.2. Rancang bangun sistem informasi penjualan yang telah dibuat pada CV. Fenny dapat dilihat dari gambar-gambar dibawah ini. Pada gambar 5. Admin/pemilik dapat menginput data barang dan dapat mencari data barang yang ada pada CV. Fenny.

Gambar 6 merupakan tampilan untuk transaksi penjualan CV. Fenny. Konsumen atau pelanggan dapat membeli beberapa kebutuhan sehari-hari yang dapat diproses oleh kasir.

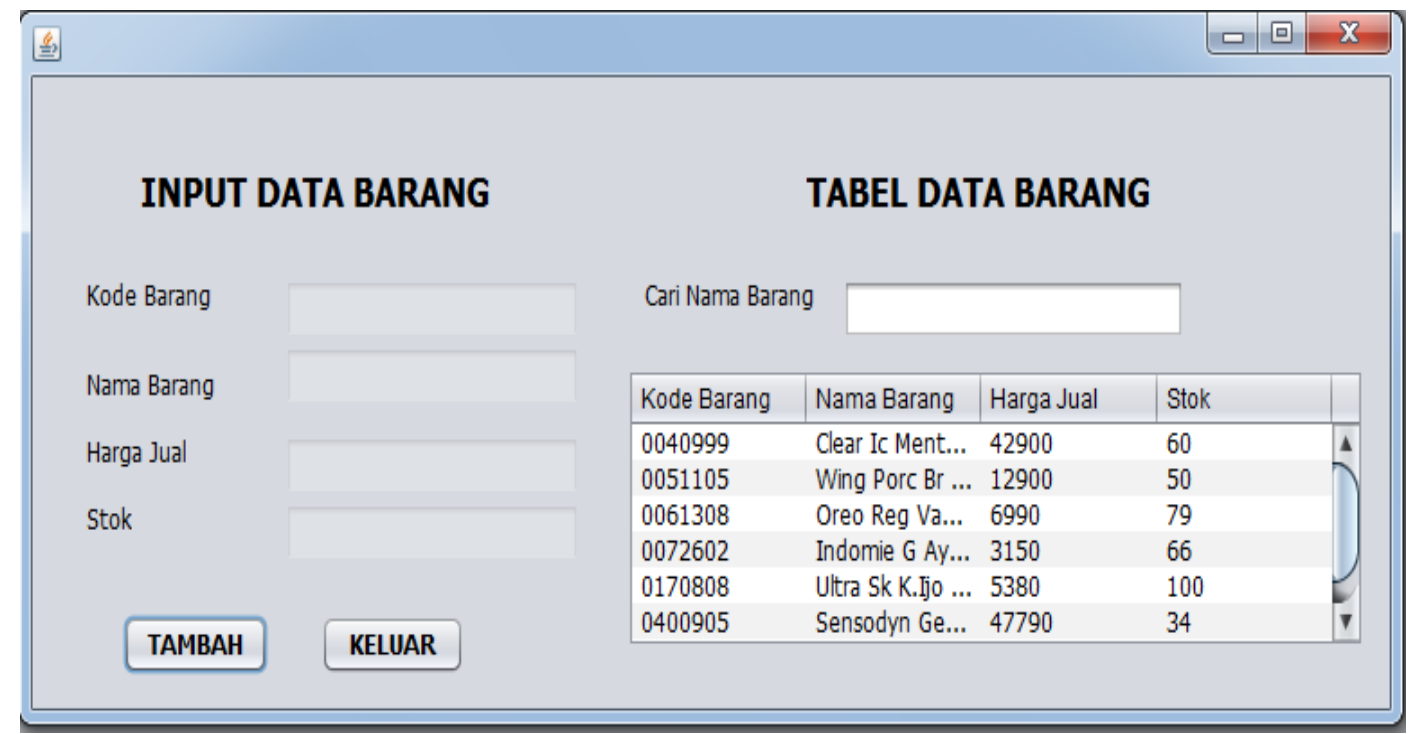

Gambar 5. Tampilan Menu Barang

Sumber: Hasil Penelitian

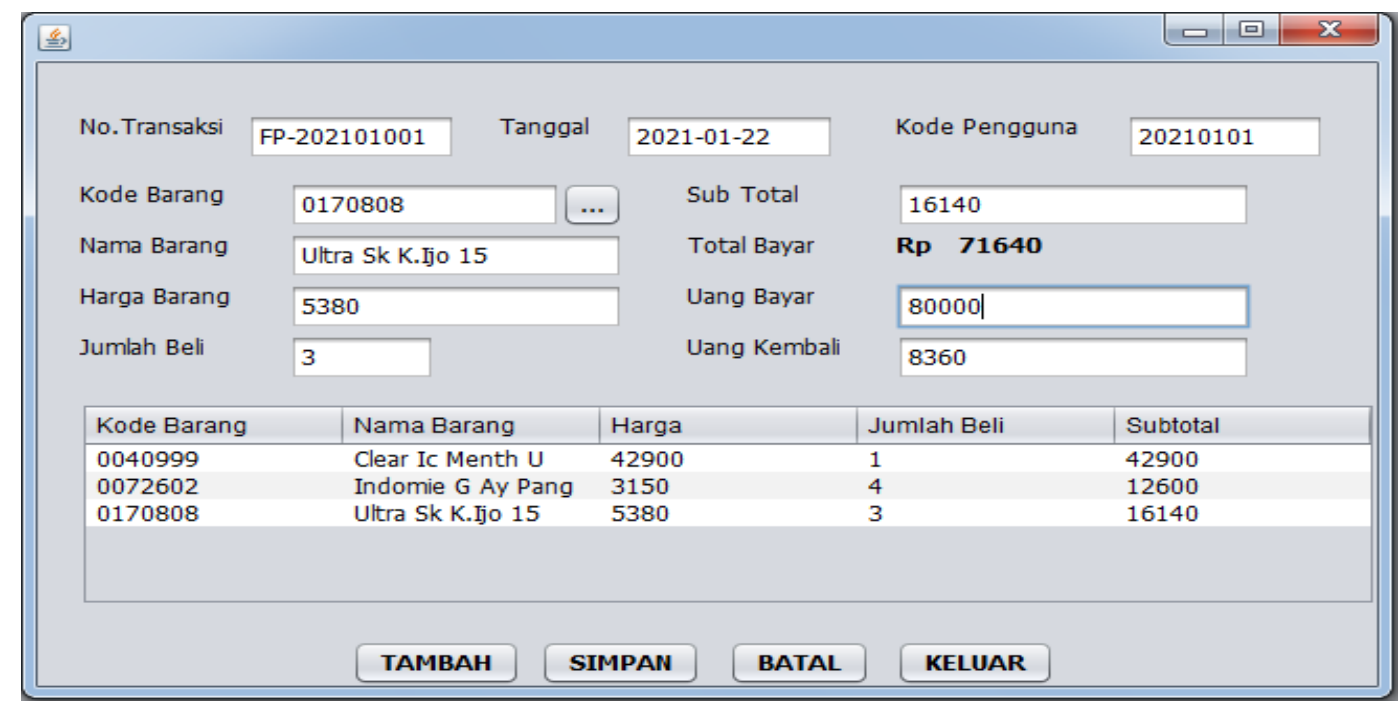

Gambar 6. Tampilan Menu Transaksi

Sumber: Hasil Penelitian 
Gambar 7 merupakan tampilan untuk mencetak laporan transaksi penjualan, dari laporan tersebut pimpinan $\mathrm{CV}$. Fenny dapat mengetahui omzet yang didapatkan setiap bulannya.

Gambar 8 merupakan tampilan untuk mengganti password pengguna agar dapat menjaga keamanan data pada saat proses transaksi dan dapat memudahkan pengguna untuk mengganti password default atau mengganti password secara berkala.

\section{Pengujian}

Setelah program sudah terselesaikan, tahap pengujian ini merupakan tahap yang paling krusial yaitu wajib melakukan pengecekan apakah terdapat error saat membuat kode program atau tidaknya. Pengujian ini menggunakan black-box testing dimana proses pengujian dilakukan untuk menemukan kesalahan agar tidak terjadi error serta memastikan output yang dihasilkan sesuai dengan yang diinginkan. Pengujian dilakukan dengan cara memberikan angket kepada user.

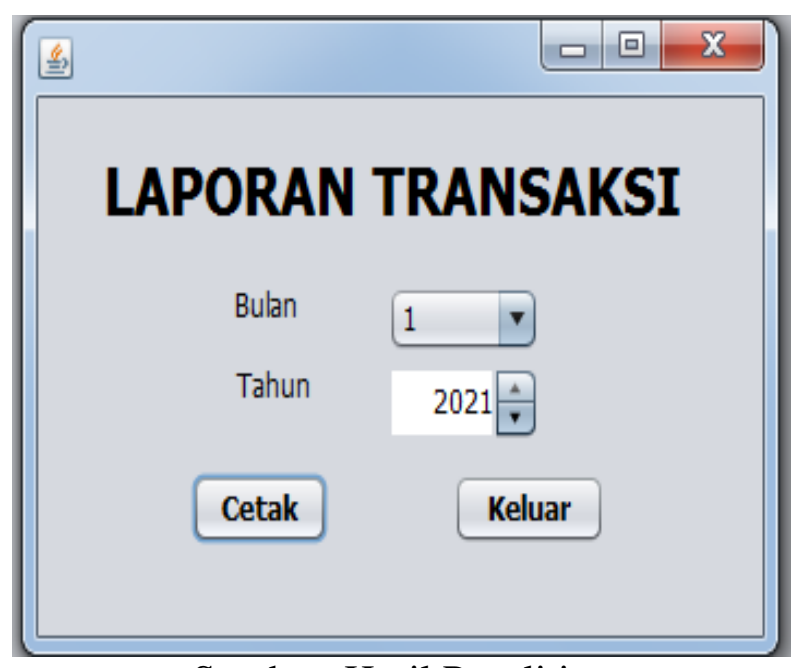

Sumber: Hasil Penelitian

Gambar 7. Tampilan Menu Laporan

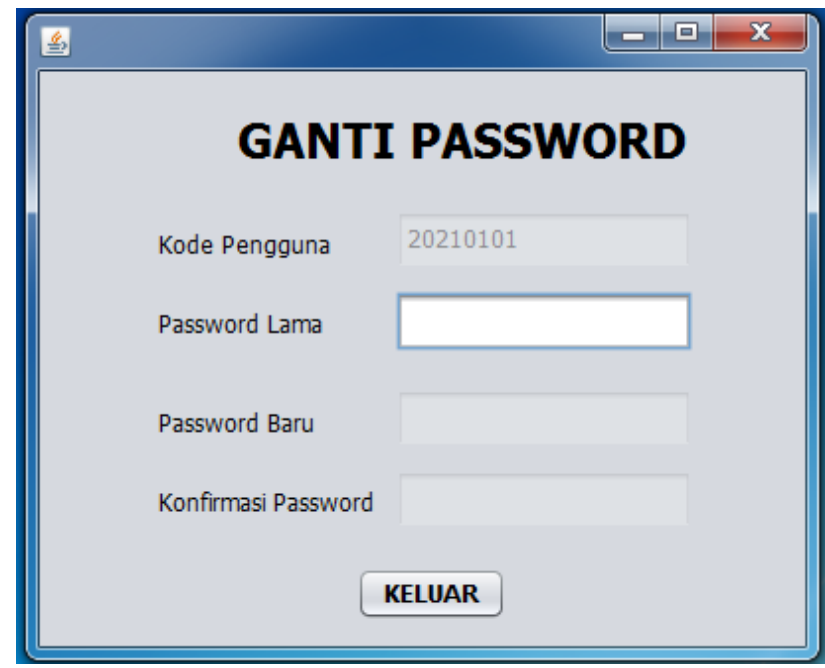

Sumber: Hasil Penelitian

Gambar 8. Tampilan Menu Ganti Password 
Tabel 2. Hasil Pengujian

\begin{tabular}{cccccccc}
\hline Partisipan & $\begin{array}{c}\text { Login } \\
\text { User }\end{array}$ & $\begin{array}{c}\text { Akses } \\
\text { Menu }\end{array}$ & $\begin{array}{c}\text { Input } \\
\text { Data } \\
\text { Barang }\end{array}$ & $\begin{array}{c}\text { Input } \\
\text { Data } \\
\text { Pengguna }\end{array}$ & $\begin{array}{c}\text { Transaksi } \\
\text { Penjualan }\end{array}$ & $\begin{array}{c}\text { Ganti } \\
\text { Password }\end{array}$ & $\begin{array}{c}\text { Mencetak } \\
\text { Laporan }\end{array}$ \\
\hline 1 & $\sqrt{ }$ & $\sqrt{ }$ & $\sqrt{ }$ & $\sqrt{ }$ & $\sqrt{ }$ & $\sqrt{ }$ & $\sqrt{ }$ \\
\hline 2 & $\sqrt{ }$ & $\sqrt{ }$ & $\sqrt{ }$ & $\sqrt{ }$ & $\sqrt{ }$ & $\sqrt{ }$ & $\sqrt{ }$ \\
\hline 3 & $\sqrt{ }$ & $\sqrt{ }$ & $\sqrt{ }$ & $\sqrt{ }$ & $\sqrt{ }$ & $\sqrt{ }$ & $\sqrt{ }$ \\
\hline 4 & $\sqrt{ }$ & $\sqrt{ }$ & $\sqrt{ }$ & $\sqrt{ }$ & $\sqrt{ }$ & $\sqrt{ }$ \\
\hline 5 & $\sqrt{ }$ & $\sqrt{ }$ & $\sqrt{ }$ & $\sqrt{ }$ & $\sqrt{ }$ & 5 \\
\hline $\begin{array}{c}\text { Sukses } \\
\text { Nilai }\end{array}$ & 5 & 5 & 5 & 5 & 5 & $100 \%$ & $100 \%$ \\
\hline
\end{tabular}

\section{Pendukung (support) pemeliharaan (maintenance)}

Tidak menutup kemungkinan sebuah aplikasi mengalami perubahan saat telah dikirimkan ke pengguna. Perubahan dapat terjadi akibat adanya kesalahan yang timbul dan tidak terdeteksi saat pengujian atau aplikasi wajib menyesuaikan diri dengan lingkungan baru. Dalam tahap ini, wajib selalu melakukan pemeliharaan pada aplikasi dari mulai backup atau restore database, penambahan fitur, dan lainlain.

\section{KESIMPULAN DAN SARAN}

Setelah dilakukan penelitian terhadap sistem informasi penjualan barang pada CV. Fenny, telah menghasilkan sebuah program berbasis dekstop yang dapat membantu menyelesaikan masalah dalam menangani sistem penjualan dan pelaporan yang masih manual. Sehingga dapat diambil kesimpulan bahwa: 1). Dengan adanya sistem informasi penjualan barang berupa program berbasis dekstop dapat meningkatkan kecepatan pada penjualan barang. 2). Dengan adanya sistem yang telah dibuat dapat mengolah transaksi penjualan dengan cepat dan tepat serta efisien waktu dan tenaga. 3). Dengan adanya sistem informasi yang telah dibangun, dapat dengan mudah mencari data transaksi atau data penjualan pada CV. Fenny. 4). Penggunaan password penting untuk bisa mengakses sistem penjualan tersebut agar tidak ada kesalahan/keamanan data dalam proses transaksi. 5). Dengan adanya penerapan sistem dapat menangani permasalahan dalam membuat laporan yang lebih akurat, cepat dan sempurna.

Adapun saran dari hasil penelitian, dalam penelitian selanjutnya dapat diupdate sistem aplikasinya dengan menambahkan data supplier dan data member. Sehingga CV. Fenny dapat mempunyai supplier lebih dari satu dan dapat memberikan promo untuk pelanggan yang sudah terdaftar menjadi member/pelanggan setia. Oleh karena itu, dengan menambahkan data konsumen atau pelanggan sehingga mempunyai kartu member. Agar pelanggan tetap setia berbelanja pada CV. Fenny. Selain itu perlu dilakukan maintenance secara berkala terhadap software dan hardware.

\section{DAFTAR PUSTAKA}

Ansirwan, Mary, T., \& Irsyadunas. (2020). Perancangan Sistem Informasi Penjualan Barang Pada Toko Bangunan MR Berbasis Desktop. E-Tech, 8(2), 1-7. Retrieved from http://ejournal.unp.ac.id/index.php/ e-tech/article/view/111008/pdf

Asroni, Jeckson, \& Basri, H. (2020). Pembuatan Aplikasi Penjualan Buku Berbasis Java Desktop dengan Netbeans. Jurnal Ilmiah Teknik Elektro, 1(1). Retrieved from 
http://journal.uml.ac.id/jtr/article/vi ew/244/pdf

Efriyanti, M., Garaika, \& Irviani, R. (2018). Analisis Implementasi Electronic Commerce Untuk Meningkatkan Omset Penjualan Butik Mery Berbasis Web Mobile. Jurnal Signaling STMIK Pringsewu, 7(2), 45-51.

Fahrezi, R. B. (2021). Program Aplikasi Penjualan Pada Restoran Harum Manis Di Cirebon. Jurnal Sosial Teknik, 3, 28-30.

Fajriani, A. (2021). Aplikasi ISO (Informasi Spesialite Obat) Indonesia Berbasis Web Menggunakan Metode Pencarian Binary Search. Jurnal Pendidikan Teknologi Informasi, 1(1), 8-16.

Lubis, B. O. (2016). Sistem Informasi Penjualan Voucher Belanja Pada PT. Plaza Iindonesia Reality Tbk. Jakarta. Jurnal Informatika, III(1), 51-62.
Maslim, M., Adithama, S. P., \& Nugroho, A. H. T. (2020). Pembangunan Sistem Informasi Penjualan Pada Usaha Mikro, Kecil, Dan Menengah (Studi Kasus : Pahala Fotokopi dan Digital Printing). Dinamisia : Jurnal Pengabdian Kepada Masyarakat, 4(1), 95-105. Universitas Lancang Kuning.

Perdana, A., Agustine, D., Sholeh, O., \& Sujana, D. (2020). Aplikasi Sistem Daily Check Drum Tire Building Di Plant H PT. Gajah Tunggal Tbk. Jurnal Ilmiah Mahasiswa Fakultas Teknik, 1, 24-28. Retrieved from https://core.ac.uk/download/pdf/288 306687.pdf

Syaputra, I., Mardika, P. D., \& Akhirina, T. Y. (2021). Sistem Informasi Penjualan Alat Berat Pada PT Altrak 1978 Berbasis Java. Seminar Nasional Riset dan Teknologi (SEMNAS RISTEK) 2021, 233-236. 
